\section{CIVILTEC}

Revista Técnico-Cientifica

de Engenharia Civil
Volume 2-n. $2-2021$

htrp://periodicos.unesc.net/engcivil

\title{
Influência do uso de coque metalúrgico como agregado de concreto no ensaio de abatimento de tronco de cone
}

Doi: http://dx.doi.org/10.18616/civiltec.v2i2.6848

\section{Introdução}

O coque metalúrgico é produzido através do processo de coqueificação, que consiste em submeter o carvão metalúrgico a um tratamento térmico na ausência de oxigênio, para produzir líquidos, gases e um resíduo sólido poroso rico em carbono (o coque), cuja temperatura, ao final do processo, fica entre $900^{\circ} \mathrm{C}$ e $1.000^{\circ} \mathrm{C}$ (AJIACO CASTRO, 2011). O coque metalúrgico possui boa condutividade térmica e elétrica, e pode ser aplicado como agregado de concreto para aumentar tais características - em concretos condutivos, por exemplo. Ao utilizar coque metalúrgico, de acordo com Almaguer, Saquetti e Coelho (2021), é possível reduzir a resistividade elétrica da base engastada dos postes entre cinco e nove vezes em comparação à dos postes convencionais. No entanto, sabe-se que o coque metalúrgico é um material poroso, característica esta que influencia nas propriedades do concreto no estado fresco, com destaque à trabalhabilidade. Nesse contexto, o presente trabalho visa analisar a influência do uso parcial de coque metalúrgico como agregado miúdo no ensaio de abatimento de tronco de cone.

\section{Metodologia}

Com o intuito de obter maior fechamento dos poros do concreto, devido ao uso de agregado poroso, optou-se por utilizar Cimento Portland Pozolânico tipo CP IV com classe de resistência à compressão de $32 \mathrm{MPa}$. O coque utilizado possui massa específica de $1,0 \mathrm{~kg} \mathrm{dm}^{-3}$ e massa unitária de 0,774 kg dm${ }^{-3}$, valores obtidos conforme NBR 16916 (ABNT, 2021) e NBR 16972 (ABNT, 2021), respectivamente. Os demais agregados foram submetidos ao ensaio utilizando o método $C$, tendo como resultado $1,571 \mathrm{~kg} \mathrm{dm}^{-3}$ para a areia e $1,483 \mathrm{~kg} \mathrm{dm}^{-3}$ para a brita basáltica. A figura 1 apresenta o coque metalúrgico em preparação para os ensaios.

\footnotetext{
1 Graduando em Engenharia Civil, Universidade do Extremo Sul Catarinense (GPDECC - Grupo de pesquisa em desempenho de estruturas e construção civil), rafaelpgurkewicz@gmail.com

2 Doutora, Departamento de Engenharia Civil, Universidade do Extremo Sul Catarinense (GPDECC - Grupo de pesquisa em desempenho de estruturas e construção civil), elainegpa@unesc.net
} 


\section{CIVILTEC}

Revista Técnico-Científica

de Engenharia Civil
Volume $2-$ n. 2 - 2021

http://periodicos.unesc.net/engcivil (a)

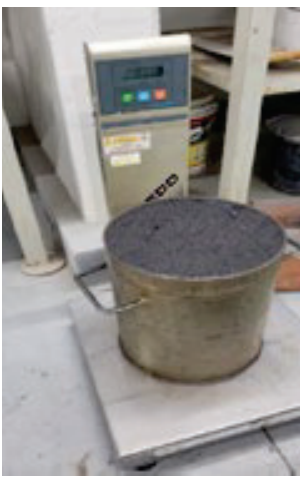

(b)

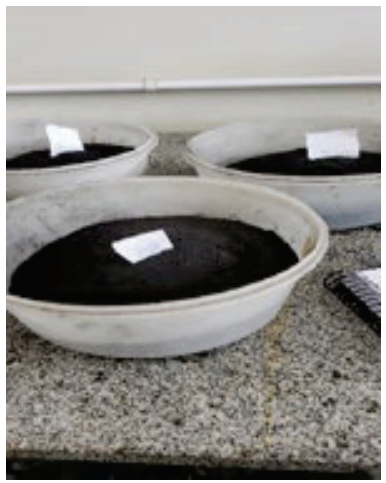

Figura 1. Coque metalúrgico sendo preparado para os ensaios: (a) de massa unitária, (b) de granulometria. (Fonte: elaboração própria)

Para definição como agregado, caracterizou-se o coque metalúrgico a partir de sua granulometria, de acordo com a NBR NM 248 (ABNT, 2003), com dimensão máxima característica de $4,75 \mathrm{~mm}$ e módulo de finura de $2,60 \pm 0,22$. Após caracterização granulométrica, definiu-se as porcentagens de substituição, tendo por base um traço de referência de 1:2:3, mostrado na tabela 1.

Tabela 1. Exemplo de formatação de tabelas. (Fonte: Souza, 2017)

\begin{tabular}{llll}
\hline $\begin{array}{l}\text { Nomenclatura da } \\
\text { mistura }\end{array}$ & $\begin{array}{l}\text { Traço utilizado } \\
\text { (cimento:areia : coque : brita) (kg) }\end{array}$ & Relação a/c & $\begin{array}{l}\text { Substituição do } \\
\text { agregado (\%) }\end{array}$ \\
\hline CC0 (referência) & $1: 2: 0: 3$ & 0,59 & 0 \\
CC7,5 & $1: 1,85: 0,15: 3$ & 0,59 & 7,5 \\
CC15 & $1: 1,7: 0,30: 3$ & 0,59 & 15 \\
CC22,5 & $1: 1: 55: 0,45: 3$ & 0,59 & 22,5 \\
\hline
\end{tabular}

A mistura dos componentes se deu em uma betoneira com capacidade total de $120 \mathrm{~L}$, rotação do tambor de $27 \mathrm{rpm}$ e $33 \mathrm{~cm}$ de diâmetro da boca, tendo por ordem a brita e a areia primeiro, junto à metade da quantidade de água; após mistura visível dos materiais, foram adicionados o cimento, o coque metalúrgico e o restante da água. A mistura se deu de forma constante até constatada a homogeneidade da pasta. Em seguida, foi realizado o ensaio de abatimento de tronco de cone com o concreto fresco, conforme NBR 16889 (ABNT, 2020). O equipamento utilizado foi umedecido, o concreto foi adicionado ao molde em três camadas, cada uma recebendo 25 golpes com a haste de socamento. Com o equipamento limpo, o molde foi removido com movimento constante e uniforme para cima e, imediatamente após a retirada do molde, foi medido o abatimento do concreto, 


\section{CIVILTEC}

Revista Técnico-Cientifica

de Engenharia Civil

\section{Volume 2 - n. 2 - 2021}

http://periodicos.unesc.net/engcivil

determinando a diferença entre a altura do molde e a altura do eixo do corpo-de-prova. 0 abatimento buscado possui valores de $100 \pm 20 \mathrm{~mm}$.

\section{Resultados}

A figura 2 mostra o abatimento obtido no ensaio de cada teor de substituição de agregado miúdo.

(a)

(b)

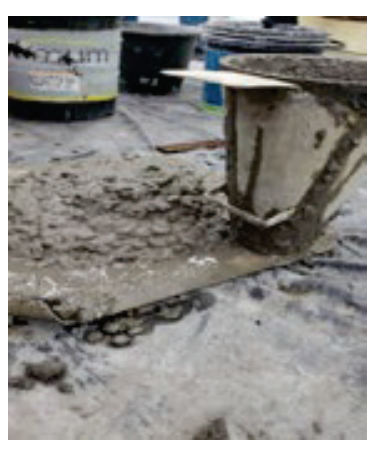

(c)

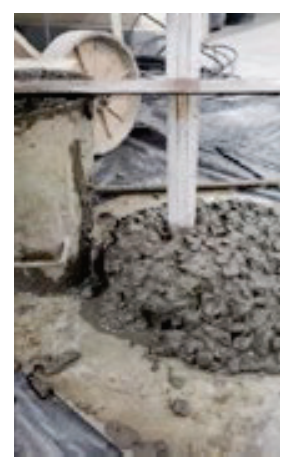

(d)
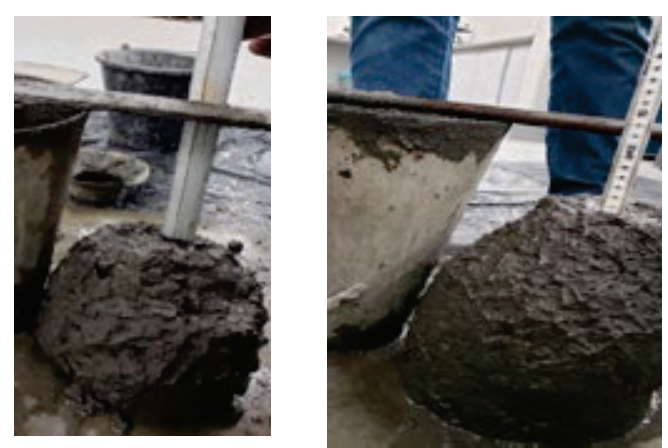

Figura 2. Abatimento obtido para cada teor de substituição: (a) CCO, (b) CC7,5, (c) CC15, (d) CC22,5. (Fonte: elaboração própria)

Verificou-se que quanto maior o teor de coque metalúrgico menor o valor do abatimento do concreto em estado fresco, sem alterar a relação água/cimento. Devido a maior porosidade do coque metalúrgico, teores mais altos de coque tendem a absorver mais a água da mistura, visto que "a água pode penetrar nos poros dos agregados" (CAMPITELI, 1987, p. 3). De acordo com Pelissari, Viviane et al., a água que serviria como lubrificante na relação água/ cimento é capturada pelo agregado e deixa de exercer esta função. A figura 3 traz os valores de abatimento obtidos para cada traço utilizado, projetando uma linha de tendência para traços intermediários e desvio padrão. 


\section{CIVILTEC}

Revista Técnico-Científica

de Engenharia Civil
Volume $2-$ n. 2 - 2021

http://periodicos.unesc.net/engcivil

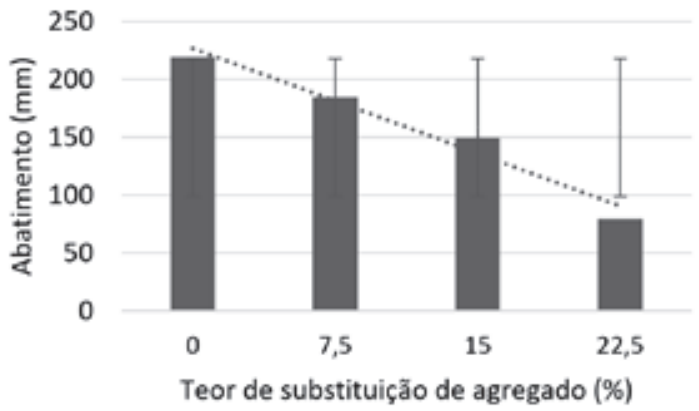

Figura 3. Valores de abatimento para cada traço utilizado. (Fonte: elaboração própria)

\section{Conclusão}

Por se tratar de um material poroso, é necessária uma maior relação água/cimento na mistura para que o abatimento seja maior que o limite inferior recomendado, uma vez que o coque em estado seco absorve parte da água. Entretanto, quanto maior a relação água/cimento, menor a resistência do concreto. Além disso, ao aumentar a relação para o traço CC22,5, o traço de referência fica com o abatimento muito maior em relação ao limite recomendado superior.

Palavras-chave: Coque Metalúrgico. Concreto. Abatimento.

\section{Referências}

AJIACO CASTRO, F. S. Evaluación del comportamiento térmico de carbones del Cerrejón, carbones coquizantes y sus mezclas en la producción de coque metalúrgico. Departamento de Química, 2011. Disponível em: <https://repositorio.unal.edu.co/handle/unal/7565>. Acesso em: 10 abr. 2021.

ALMAGUER, Hugo Armando Dominguez; SAQUETTI, Deyvi; COELHO, Vilson Luiz. Um Estudo do Uso da Base Engastada dos Postes de Concreto Como Aterramento para Redes Aéreas de Distribuição. Revista de Engenharia e Pesquisa Aplicada, v. 6, n. 1, p. 9-21, 2021. Disponível em: <http://www. revistas.poli.br/ anais/index.php/repa/article/view/1369/693>. Acesso em: 9 maio 2021.

ASSOCIAÇÃO BRASILEIRA DE NORMAS TÉCNICAS. NBR 16889: concreto - determinação da consistência pelo abatimento do tronco de cone. Rio de Janeiro, 2020.

NBR 16916: agregado miúdo - determinação da densidade e da absorção de água. Rio de Janeiro, 2021. de Janeiro, 2021.

NBR 16972: agregados - determinação da massa unitária e do índice de vazios. Rio Janeiro, 2003.

NBR NM 248: agregados - determinação da composição granulométrica. Rio de

CAMPITELI, V. C. Porosidade do concreto. Escola Politécnica da USP, 1987. Disponível em: <http:// www.pcc.poli.usp.br/files/text/publications/BT_00009.pdf>. Acesso em: 15 set. 2021.

PELISSARI, Viviane et al. Absorção de água de amassamento em concretos produzidos com agregados reciclados. Brazilian Applied Science Review, v. 4, n. 1, p. 51-69, 2020. Disponível em: <https://www.brazilianjournals.com/index.php/BASR/article/view/6079>. Acesso em: 15 set. 2021. 